\title{
KEFEKTIVITASAN MACROMEDIA FLASH PENDIDIKAN SEKS DALAM MEMPERSIAPKAN MASA PUBERTAS ANAK TUNAGRAHITA DI SLB B/C AL AZHAR WARU SIDOARJO
}

\author{
Dian Puspa Dewi \\ PG PAUD Universitas PGRI Adi Buana Surabaya \\ dianpuspadewi90@gmail.com
}

\begin{abstract}
Sexual development of mental retardation's children follows the physical development, thus experiencing a similar development with the normal ones. Those students have difficulty in understanding abstract information about the physical changes during puberty. Therefore, through the medium of learning macromedia flash, the sex education learning can be understood by them. This study aims to determine the effectiveness of using multimedia in teaching sex education as preparation for mental retardation's students during puberty in SLB B/C SLB Al Azhar Waru Sidoarjo. The subjects were mental retardation's students in that schools. Data collection techniques used in this research was shaped test objective tests. The design model used in this study is one group pretest-posttest design (treatment by subject design). Data analysis techniques used by the author in this research was a non-parametric analysis techniques that rank test Wilcoxon signed Sign marked tests (Wilcoxon Sign Rank Test). Based on the data analysis and discussion of the results of research, known that the $\mathrm{Z}$ count $=-2070$ with $\mathrm{P}=0.038$ at significance level of $5 \%$. The results are smaller than 0.05 can be proven true. Based on those explanations it can be concluded that the alternative hypothesis which states "Learning to use Macromedia Flash is effective in teaching sex education for mental retardation's students in SLB B / C Al Azhar Waru Sidoarjo" can be proven true.

Keywords: Macromedia Flash, sex education, children with intellectual disability
\end{abstract}

\begin{abstract}
ABSTRAK
Perkembangan seksual anak tunagrahita mengikuti perkembangan fisiknya, sehingga mengalami perkembangan yang sama dengan perkembangan seksual teman sebayanya. Siswa tunagrahita mengalami kesulitan mencerna informasi abstrak mengenai perubahan fisiknya selama masa pubertas. Oleh karena itu melalui media pembelajaran macromedia flash pendidikan seks siswa tunagrahita diberikan pemahaman dan penjelasan yang berkaitan dengan masa pubertasnya. Penelitian ini bertujuan untuk mengetahui kefektivitasan multimedia pembelajaran pendidikan seks terhadap pemahaman dalam mempersiapkan masa pubertas anak tunagrahita di SLB B/C SLB Al Azhar Waru Sidoarjo. Subjek penelitian ini adalah siswa tunagrahita di Sekolah Luar Biasa. Teknik pengumpulan data yang dipakai dalam penelitian ini adalah teknik tes berbentuk tes objektif. Model desain yang digunakan dalam penelitian ini adalah one group pretest-posttest design (treatment by subject design). Teknik analisis data yang digunakan penulis dalam penelitian ini adalah dengan menggunakan teknik analisis non-parametrik yaitu tes rangking bertanda Sign tes bertanda Wilcoxon (Wilcoxon Sign Rank Test). Berdasarkan analisis data dan pembahasan hasil penelitian, diketahui bahwa hasil $\mathrm{Z}$ hitung $=-2.070$ dengan $\mathrm{P}=0.038$ pada taraf signifikasi $5 \%$. Hasil tersebut lebih kecil dari 0,05 dapat terbukti kebenarannya. Berdasarkan penjelasan tersebut maka dapat disimpulkan bahwa hipotesis alternative yang menyatakan "Pembelajaran menggunakan macromedia flash pendidikan seks efektif bagi anak tunagrahita di SLB B/C Al Azhar Waru Sidoarjo" dapat terbukti kebenarannya.

Kata kunci: Macromedia flash, pendidikan seks, anak tunagrahita
\end{abstract}


138 | Premiere Educandum, Volume 6 Nomor 2, Desember 2016, 137 - 145

\section{A. PENDAHULUAN}

Anak tunagrahita memiliki hambatan pada beberapa aspek dalam kehidupannya antara lain aspek kemampuan akademik, sosial dan emosional. Namun pada aspek perkembangan fisik anak tunagrahita hampir atau sama dengan anak normal pada umumnya. Seperti yang dijelaskan oleh Soemantri (2007) bahwa fungsi-fungsi perkembangan anak tunagraita ada yang sama atau hampir menyamai anak normal, adapula yang tertinggal jauh oleh anak normal. Perkembangan fisik disini termasuk juga pada tumbuh kembang anak tunagrahita menuju masa dewasa seperti pertumbuhan bagian-bagian tertentu pada tubuhnya. Anak tunagrahita mengalami hal yang tidak jauh berbeda dari anak normal dalam munculnya ciri-ciri pada masa pubertasnya.

Clennen dalam Maholtra (2012) menejelaskan perkembangan seksual anak tunagrahita mengikuti perkembangan fisik mereka bukan perkembangan kognitif mereka. Hal ini dapat diartikan bahwa perkembangan seksual anak tunagrahita yang termasuk di dalamnya permasalahan munculnya ciri-ciri masa pubertas pada anak tunagrahita kurang lebih sama dengan anak normal pada umunya.

Permasalahan akan muncul saat kita menyadari bahwa anak tunagrahita secara fisik tumbuh seperti anak pada umunya, namun mereka tidak dapat memahami arti pertumbuhan dan perkembangan tersebut. Sedangkan banyak hal yang harus dilakukan dan dihindari saat remaja mulai tumbuh dan berkembang secara fisik. Hal inilah yang menjadi sorotan, bahwa dalam mempersiapkan masa pubertasnya anak tunagrahita memerlukan bantuan orang dewasa di sekitarnya untuk memberikan pemahaman yang baik sesuai dengan karakteristiknya. Morano (2001) memaparkan, mayoritas tunagrahita berkembang normal sesuai dengan karakteristik seksualnya tetapi membutuhkan bantuan lebih dalam memahamai perubahannya.

Salah satu upaya yang dapat dilakukan dalam membantu anak tunagrahita dalam mempersiapkan masa pubertasnya adalah dengan 
menjlaskannya sesuai dengan karakteristiknya. Dimana anak tunagrahita tidak dapat memahami hal secara abstrak. Oleh karena itu, media pembelajaran dapat digunakan untuk menjelaskan hal tersebut kepada anak tunagrahita dalam kegiatan pembelajaran di kelas.

Macromedia Flash merupakan sebuah software yang banyak digunakan dalam menjelaskan konsep abstrak kepada peserta didik dalam pembelajaran di kelas. Berdasarkan beberapa kelebihan software tersebut peneliti memanfaatkannya untuk menjelaskan konsep abstrak dari pertumbuhan dan perkembangan seksual seseorang. Hal ini dilakukan sebagai upaya membantu anak tunagrahita dalam mempersiapkan masa pubertasnya.

Berdasarkan pada penelitian sebelumnya dimana peneliti telah mengembangkan multimedia pembelajaran pendidikan seks dalam mmepersiapkan masa pubertasnya, dalam penelitian ini multimedia yang telah dikembangkan tersebut akan diaplikasikan kepada anak tunagrahita di SLB B/C Al Azhar Waru Sidoarjo. Materi dalam multimedia pembelajaran ini akan diintegrasikan pada pembelajaran IPA di kelas VI.

Hipotesis dari penelitian ini adalah Pembelajaran menggunakan macromedia flash pendidikan seks dalam mempersiapkan masa pubertas anak tunagrahita efektif bagi anak tunagrahita di SLB B/C Al Azhar Waru Sidoarjo.

\section{B. METODE PENELITIAN}

Penelitian ini bertujuan untuk mengetahui kefektivitasan multimedia pembelajaran pendidikan seks terhadap pemahaman dalam mempersiapkan masa pubertas anak tunagrahita di SLB B/C SLB Al Azhar Waru Sidoarjo.

Subjek penelitian ini adalah siswa tunagrahita di Sekolah Luar Biasa sebanyak 5 orang. Teknik pengumpulan data yang dipakai dalam penelitian ini adalah teknik tes berbentuk tes objektif. Instrumen tes ini telah diujicoba validitasnya dengan menggunakan product moment dan reliabilitasnya dengan mengunakan teknik belah dua gasal genap dengan rumus Spearman Brown. Model desain yang digunakan dalam penelitian ini adalah one group 
140 | Premiere Educandum, Volume 6 Nomor 2, Desember 2016, 137 - 145

pretest-posttest design (treatment by subject design). Dimana sebelum dan sesudah diberikan treatment yaitu penggunaan macromedia flash pendidikan seks dalam pembelajaran diberikan test untuk mengetahui pemahaman siswa sebelum dan setelah menggunakan media dalam pembelajaran. Teknik analisis data yang digunakan penulis dalam penelitian ini adalah dengan menggunakan teknik analisis nonparametrik yaitu tes rangking bertanda Sign tes bertanda Wilcoxon (Wilcoxon Sign Rank Test)

\section{HASIL PENELITIAN}

\section{Data Hasil Pre Test}

Deskripsi data nilai, deskriptif statistik, deskripsi frekuensi, dan grafik histogram pemahaman anak tunagrahita sebelum perlakuan (pre test). Data kemampauan pemahaman pendidikan seks anak tunagrahita sebelum dilakukan perlakuan (pre test), diperoleh dari hasil tes treatment dalam pelaksanaan eksperimen. Hasil dari eksperimen tersebut diperoleh data sebagai berikut:
Tabel 1. Data Nilai Pretes

\begin{tabular}{cc}
\hline Nama Siswa & Nilai pre test \\
\hline RZ & 45 \\
YL & 55 \\
UM & 60 \\
RK & 55 \\
DL & 50 \\
\hline
\end{tabular}

Sumber data : Data primer (2015)

Tabel 2. Deskriptif Statistik

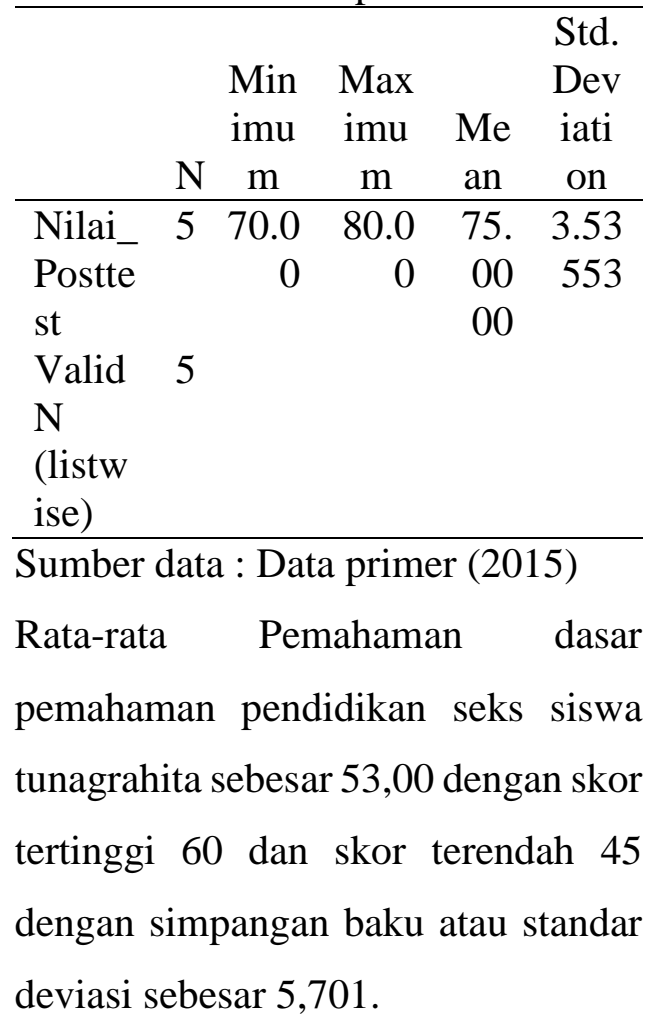

\section{Data Hasil Post Tes}

Deskripsi data nilai, deskripsi statistik, deskripsi frekuensi, dan grafik histogram pemahaman pendidikan seks siswa tunagrahita sesudah perlakuan (post test). Data nilai pendidikan seks siswa tunagrahita sesudah diberikan perlakuan (post test) diperoleh data nilai sebagai berikut: 
Tabel 3. Deskriptif Statistik diperoleh nilai 75 . Selisih nilai rataVariabel

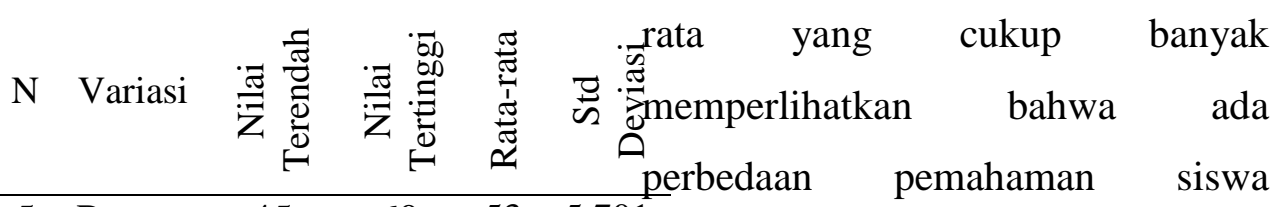

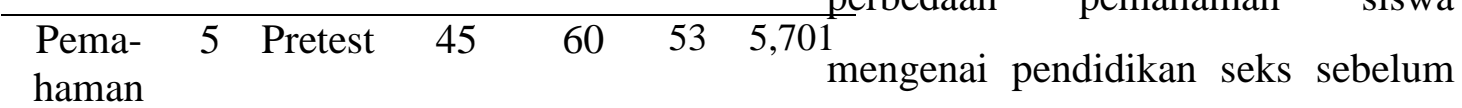
pendidi- 5 Post $70 \quad 80 \quad 75$ 3,535dan setelah dilakukan perlakuan/ kan test treatment. Apakah perbedaan itu seks

Sumber data : data primer (2015)

Data di atas setelah dihitung diperoleh hasil sebagai berikut ratarata pemahaman siswa sebesar 75,00 dengan skor tertinggi 80 dan skor terendah 70 dengan simpangan baku standar deviasi sebesar 3,535.

Adapun ringkasan data hasil pretest dan postest adalah sebagai berikut:

Tabel 4. Deskriptif Statistik

\begin{tabular}{|c|c|c|c|c|c|}
\hline & $\mathrm{N}$ & $\begin{array}{c}\text { Min } \\
\text { imu } \\
\text { m }\end{array}$ & $\begin{array}{c}\text { Max } \\
\text { imu } \\
\text { m }\end{array}$ & $\begin{array}{c}\mathrm{Me} \\
\text { an }\end{array}$ & $\begin{array}{c}\text { Std. } \\
\text { Dev } \\
\text { iati } \\
\text { on }\end{array}$ \\
\hline Nilai_ & 5 & 45.0 & 60.0 & 53. & 5.70 \\
\hline $\begin{array}{l}\text { Postte } \\
\text { st } \\
\text { Valid } \\
\mathrm{N} \\
\text { (listw } \\
\text { ise) }\end{array}$ & 5 & 0 & 0 & $\begin{array}{l}00 \\
00\end{array}$ & 088 \\
\hline
\end{tabular}

tersebut diatas, diketahui bahwa ratarata pemahaman pendidikan seks pada waktu pretest diperoleh nilai 53 dan nilai rata-rata posttest pemahaman pendidikan seks bermakna secara statistik, akan diuji pada analisis data.

Berikut ini penulis sajikan gambar histogram

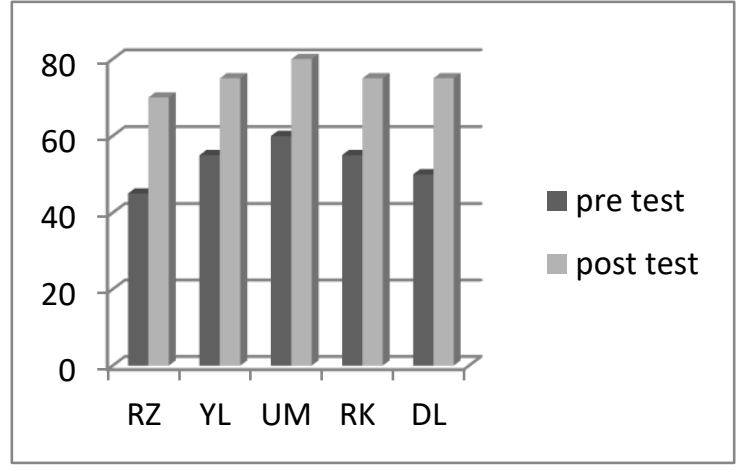

Gambar 1. Histrogram Pemahaman Pendidikan Seks siswa tunagrahita sebelum perlakuan (pretest) dan Sesudah Perlakuan (Posstest)

Sumber data: data primer (2015)

\section{Pembuktian hipotesis}

Kaidah yang dipakai dalam penelitian ini adalah membandingkan Asymp. Sig. (2-tailed) dengan taraf signifikansi $(\alpha)$ maka dapat diketahui keputusan ditolak atau diterimanya hipotesis nihil. Berdasarkan analisis di atas diperoleh nilai Asymp. Sig. (2- 
tailed) $=0.038<0.05$ maka $\mathrm{Ho}$

ditolak dan Ha diterima. Berdasarkan

pernyataan di atas dapat disimpulkan

bahwa pembelajaran dengan

menggunakan macromedia flash

pendidikan seks efektifbagi siswa tunagrahita di SLB B/C Al Azhar Waru Sidoarjo.

\section{PEMBAHASAN}

Berdasarkan

pembuktian

hipotesis di atas maka dapat dikaji pembahasan hasil penelitian sebagai berikut: hasil analisis deskriptif dapat diperoleh nilai rata-rata post tes lebih besar 88,83 dari pada nilai rata-rata pre tes 40,33. Hasil analisis non parametrik diperoleh nilai $Z=-2.070$ dengan $\mathrm{P}=0.038$, maka hipotesis berbunyi macromedia flash pendidikan seks efektif pada pembelajaran bagi siswa tunagrahita di SLB B/C Al Azhar Waru Sidoarjo dan diterima kebenarannya. Kesimpulan penelitian menyatakan bahwa macromedia flash pendidikan seks efektif pada pembelajaran bagi siswa tunagrahita di SLB B/C Al Azhar Waru Sidoarjo

Pendidikan seks penting diberikan kepada siswa tunagrahita. Hal ini dikarenakan masa pubertas anak tunagrahita sama dengan masa pubertas anak normal pada uumnya, sehingga ciri-ciri perode pubertas anak tunagrahita pun sama dengan anak normalnya. Mappiare (1982) membedakan ciri-ciri pubertas individu menjadi ciri-ciri utama dan umum; dan ciri-ciri yang erat bersangkutan langsung dengan pertumbuhan dan perkembangan biologis dan psikologis. Berdasarkan hal tersebut, akan menimbulkan permasalahan pada anak tunagrahita saat menghadapi masa pubertas.

Permasalahannya adalah terletak pada pemahaman anak tunagrahita terhadap apa yang dialaminya dalam masa puberitas tidak sesuai dengan usia mentalnya. Morano (2001) menjelaskan bahwa anak tunagrahita memerlukan bantuan yang lebih dalam memahami perubahannya. Memberikan bantuan pemahaman mengenai perubahan yang terjadi pada diri anak tunagrahita terkait perkembangan seksualnya di sekolah, dapat disampaikan melalui pendidikan seks salah satunya melalui Macromedia flash pendidikan seks.

Berdasarkan penelitian yang telah dilakukan peneliti terdapat 
peningkatan nilai dari sebelum menggunakan media dan setelah menggunakan media. Pembelajaran menggunakan Macromedia flash pendidikan seks menimbulkan kesenangan pada siswa dan meningkatkan konsentasi serta interaksi langsung antara peserta didik dengan media pembelajaran. Selain itu, pelajaran lebih menarik perhatian siswa dan memotivasi siswa dalam belajar. Indriana (2011) kelebihan dari media macromedia flash yang bersifat audio visual adalah bisa diputar berulang-ulang sesuai dengan kebutuhan siswa.

Hal ini didukung penelitian Miswanto (2011) mengenai Pengembangan Perangkat Pembelajaran IPA SD Disertai Media Berbasis Macromedia Flash Pokok Bahsan Sistem Tata Surya. Sistem tata surya merupakan salah satu pokok bahasan IPA SD yang bersifat abstrak sehingga sulit dipahami siswa, sehingga dikembangakan perangkat pembelajaran IPA SD disertai media berbasis Macromedia Flash. Hasil dari penelitian ini adalah perangkat pembelajaran IPA SD disertai media berbasis Macromedia
Flash dapat meningkatkan dan menuntaskan hasil belajar siswa SD.

\section{E. SIMPULAN DAN SARAN}

\section{Simpulan}

Berdasarkan analisis data dan pembahasan hasil penelitian, diketahui bahwa hasil $\mathrm{Z}$ hitung = 2.070 dengan $\mathrm{P}=0.038$ pada taraf signifikasi 5\%. Hasil tersebut lebih kecil dari 0,05 dapat terbukti kebenarannya. Berdasarkan penjelasan tersebut maka dapat disimpulkan bahwa hipotesis alternative yang menyatakan "Pembelajaran menggunakan macromedia flash pendidikan seks efektif bagi anak tunagrahita di SLB B/C Al Azhar Waru Sidoarjo" dapat terbukti kebenarannya.

\section{Saran}

Berdasarkan penelitian yang telah dilakukan terdapat beberapa hal yang disarankan oleh peneliti, antara lain:

1. Bagi guru

Sebagai subjek yang mentransfer informasi kepada peserta didik sebaiknya guru menggunakan berbagai metode dan media dalam pembelajaran. Terlebih materi yang bersifat abstrak 
144 | Premiere Educandum, Volume 6 Nomor 2, Desember 2016, 137 - 145

sebaiknya lebih banyak

menggunakan inovasi agar pesan

yang tersampaikan dapat tepat

guna. Salah satunya adalah

dengan menggunakan media

macromedia flash pendidikan

seks dalam memberikan

pemahaman

mengenai

pendidikan seks terkait dengan

pubertas terhadap siswa

tunagrahita.

2. Bagi siswa

Siswa dapat mengoperasikan macromedia flash pendidikan seks secara mandiri baik di sekolah maupun di rumah, namun harus dengan pendampingan dan penjelasan mengenai materi yang terdapat pada media pembelajaran dari orang dewasa di sekitarnya.

3. Bagi sekolah

Pihak sekolah sebaiknya semakin melengkapi fasilitas pembelajaran agar dapat menunjang kegiatan pembelajaran di kelas bagi siswa tunagrahta terkait dengan perkembangan IPTEKS.

4. Bagi orang tua
Sebagai orang yang mendampingi siswa di rumah saat anak mengoperasikan macromedia flash pendidikan seks di rumah sebaiknya diberikan pendampingan dan diberikan penjelasan kepada anak.

\section{DAFTAR RUJUKAN}

Boehning, Alison. 2006. Sex Eduacation For Student With Disabilities. Indiana University.

Chomaria, Nur. 2012. Pendidikan Seks Untuk Anak. Solo: Aqwam Jembatan Ilmu.

Efendi, Mohammad. 2006. Pengantar Psikopedagogik Anak Berkelainan. Jakarta: Bumi Aksara.

Indriana, Dina. 2011. Ragam Alat Bantu Media Pengajaran. Jogjakarta:Diva Press.

Maholtra, Neera. 2012. Unruly Policies: The Politics of In/Equalities In Sexuality Education For Students With Intellectual Disabilities In School Settings. Portlandia: Portland State University.

Mappiare, Andi. 1982. Psikologi Remaja. Malang : Usaha Nasional.

Miswanto.2011. Pengembangan Perangkat Pembelajaran IPA SD Disertai Media Berbasis Macromedia Flash Pokok Bahsan Sistem Tata Surya. Surabaya: Pascasarjana UNESA Tidak dipublikasikan. 
Morano, Jamie P. 2001. Sexual Abuse

Of The Mentally Retarded Patient: Medical And Legal Analysis For The Primary Care Physician. Primary Care Comapnion J Clin Psychiatry. Vol. 3 No.3.

Nichy. 1992. Sexuality Education for Children and Youth With Disability. Washington: New Digest Inc. Vol. 1 No. 3.

Somantri, Sutjihati. 2007. Psikologi Anak Luar Biasa. Bandung : PT Refika Aditama.

$\begin{array}{crr}\text { Wiriawan. } 2013 . & \text { Program } \\ \text { Bimbingan } & \text { Seks } & \text { Untuk } \\ \text { Orangtuan } & \text { Pada } & \text { Anak } \\ \text { Tunagrahita } & & \text { Ringan. } \\ \text { Universitas } & & \text { Pendidikan } \\ \text { Indonesia. } & & \text { Tidak } \\ \text { Dipublikasikan. } & \end{array}$

